\title{
Conditioning an Underground Gas Storage Site to Well Pressures
}

\author{
M. Le Ravalec-Dupin ${ }^{1}$, B. Coureaud ${ }^{2}$, L. Nicolas ${ }^{2}$ and Frédéric Roggero' \\ 1 Institut français du pétrole, 1 et 4, avenue de Bois-Préau, 92852 Rueil-Malmaison Cedex - France \\ 2 Gaz de France, 361, avenue du Président-Wilson, BP33, 93211 Saint-Denis-La Plaine Cedex - France \\ e-mail: mickaele.le-ravalec@ifp.fr - bertrand.coureaud@gazdefrance.com - laurent-m.nicolas@gazdefrance.com - frederic.roggero@ifp.fr
}

Résumé - Calage d'un site de stockage de gaz par des données de pression - Cet article concerne la modélisation d'un site souterrain de stockage de gaz, situé près de Paris (France), en considérant simultanément les données géologiques et les pressions mesurées aux puits.

L'historique de production disponible comprend deux périodes. Le gaz coussin est injecté pendant une première période, qui s'étale sur sept ans. Il s'agit avant tout d'une période de remplissage. La deuxième période, d'une durée de dix ans, est consacrée à l'exploitation du site. On injecte du gaz l'été pour réalimenter les réserves et on l'extrait l'hiver en fonction de la demande des consommateurs. Le fonctionnement du stockage est assuré par une douzaine de puits. Pendant ces deux périodes, les pressions sont enregistrées dans onze puits d'observation, situés autour du site de stockage. Dans cette étude, seules les données collectées pendant la première période sont utilisées pour contraindre le modèle de réservoir. Les données relatives à la seconde période sont mises de côté. Elles permettront ultérieurement d'apprécier la qualité du modèle construit à partir des données de la première période.

Un processus assisté de calage d'historique est mis en place pour intégrer conjointement les données géologiques et les données de pression dans la modélisation du réservoir. Ce processus fait intervenir la méthode de déformation graduelle. Il permet d'ajuster, au cours du processus de calage, des paramètres déterministes ainsi que des paramètres stochastiques. On montre que les paramètres les plus influents dépendent des propriétés pétrophysiques : on identifie, par exemple, les moyennes des porosités et les coefficients liant les porosités et les perméabilités. Pour l'étude considérée, les paramètres stochastiques s'avèrent être du deuxième ordre : ils n'affectent que très peu le processus de calage. Le modèle optimal de réservoir obtenu après calage corrobore les données géologiques et les pressions enregistrées aux puits.

La méthodologie développée se caractérise essentiellement par les possibilités qu'elle offre en ce qui concerne la gestion d'un workflow. Elle permet d'intégrer toutes les étapes de la construction d'un modèle de réservoir depuis la création du modèle géologique à l'échelle fine jusqu'à la simulation des écoulements de fluide sur le modèle grossier. Le workflow, une fois stocké, peut être répété : l'influence de nombreux paramètres, tant déterministes que stochastiques, peut être analysée. Enfin, la technique proposée permet d'effectuer rapidement des tests préliminaires de calage et d'élaborer au final un modèle fin cohérent avec l'ensemble des données disponibles. La cohérence améliorée vis-à-vis des données conduit à une réduction des incertitudes sur les prédictions relatives au comportement dynamique du réservoir. 


\begin{abstract}
Conditioning an Underground Gas Storage Site to Well Pressures - This paper is concerned with the integrated modelling of an underground gas storage (UGS) site, considering geological data as well as production data.

The production history for this UGS, located in an aquifer close to Paris, France, consists of two periods. The first one is a 7-year filling period for which the cushion gas was injected. The second one is a 10year cycling period for which gas was injected during the summer to replenish the reserves and withdrawn during the winter according to the demand. Gas storage was performed through a dozen wells. During these two periods, pressures were recorded in 11 observation wells located all around the site. The first period data only are used to constrain the reservoir model. The second period data are used for comparison purposes.

An assisted history-matching process based on the gradual deformation method was implemented to integrate production history jointly with geological data into reservoir models. By use of this innovative technique, both stochastic and deterministic parameters were accounted for. We show that the most influential parameters are related to the petrophysical properties (porosity means, coefficients defining the relations between porosity and permeability). The stochastic parameters are of second order only: they did not impact the matching process. The optimal reservoir model deduced from the matching procedure reproduced the static data and the pressures recorded for almost all the wells.

The assisted history-matching methodology developed is especially powerful for managing a workflow integrating every steps from fine grid model creation to fluid flow simulation, handling rapid preliminary history-matching tests, analyzing the influence of several deterministic and stochastic parameters, determining fine grid reservoir models consistent with all the available data, and lastly reducing uncertainty in predictions.
\end{abstract}

\section{INTRODUCTION}

Porous aquifer formations (usually sands, sandstones or carbonates at depths of about 1500 to $6000 \mathrm{ft}$ ) are the most common means of storing natural gas, in any quantity, especially very large volumes. These underground gas storages (UGS) provide the swing capacity required to meet the variations in demand. Gas is injected during the summer when supply exceeds demand and withdrawn during winter to cover peak demands. Similarly to oil and gas production fields, gas storage management requires an accurate reservoir modelling in order to monitor the gas bubble extension and maximize the potential deliverability of the UGS. The maximum withdrawal rate will depend on the number of wells, the technical capabilities, the pressure, but also on the characteristics of the porous rock. Such modelling calls for relevant information provided for instance by pressures recorded in observation wells all along the production cycles (dynamic data) and by geological knowledge (static data).

An assisted history-matching (AHM) process based upon the gradual deformation method is implemented to integrate production history jointly with geological data into reservoir models. The gradual deformation method is a geostatistical parameterization technique introduced by $\mathrm{Hu}$ [1] that allows for varying any given attribute distribution from a few parameters, termed deformation parameters, while preserving the overall spatial variability. In other words, the porosity or permeability fields that populate the reservoir model can be perturbed in order to reduce the dynamic data misfit while keeping the consistency with the geological knowledge.
Additionally, the other parameters (e.g., correlation lengths, means, aquifer activity coefficients, etc., termed deterministic because they do not depend on any random seed, can be simultaneously modified during the matching process. These properties make the gradual deformation based matching procedures very attractive.

This innovative matching process was applied to characterize a gas storage reservoir, located in an aquifer close to Paris, France. A dozen wells were alternatively used as injectors and producers while pressures were recorded in 11 observation wells over 17 years. Our objective was to integrate these pressure data in the reservoir model by optimizing a few deterministic parameters as well as the permeability and porosity distributions.

\section{DESCRIPTION OF THE SITE AND THE AVAILABLE DATA}

\subsection{Reservoir Features}

The underground gas storage flow model consists of 4 embedded grid levels (Fig. 1). The coarsest level, the first one, consists of $25 * 23 * 2$ gridblocks with $D X=D Y=13.5 \mathrm{~km}$ and a nonconstant thickness. The fourth level contains $33 * 21 * 9$ gridblocks with thickness varying with location, and $D X=D Y=750 \mathrm{~m}$. This grid was used to build the flow model. However, a geological model was also built for which the fourth level was refined over a $330 * 210 * 9$ grid. In this case, $D X=D Y=75 \mathrm{~m}$. 


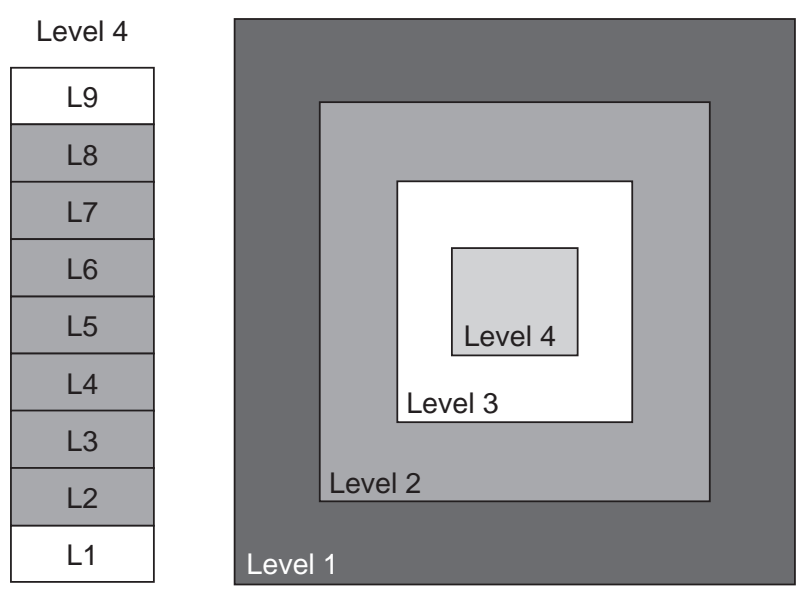

Figure 1

Description of the fourth-level underground gas storage site.

We aim at focusing on the fourth level and more especially on the 7 intermediate layers (L2-L8), the 2 outermost layers (L1 and L9) being aquifers. Gas storage is performed in the L2-L8 layers. Roughly speaking, gas storage is performed in the middle of level 4 . The properties of levels 1,2 and 3 are not modified during the history-matching process.

\subsection{Petrophysical Data}

The L2-L8 layers are considered as independent. The analysis of static well data provides information about porosity means and variances as well as porosity-permeability relationships for each of the 7 studied layers (Table 1 and Fig. 2). These relations express as:

$$
\log _{10}(k)=A \phi+B
$$

$A$ and $B$ are constants, $\phi$ is the porosity and $k$ the permeability. Horizontal permeability is assumed to be isotropic, while the ratio of the vertical permeability to the horizontal one is 0.1 . We observe that layer L4 acts as a barrier to flow.

The available static well data did not allow for determining any valid variogram model describing the spatial variations in porosity. Thus, we consider the same spherical and isotropic variogram with a range of $250 \mathrm{~m}$ for all of the 7 layers.

\subsection{Pressure Data}

The production history for this UGS consists of two periods. The first is a 7-year filling period for which the cushion gas is injected. The second is a 10-year cycling period for which gas is injected during the summer to replenish the reserves and is withdrawn during the winter according to demand.
Gas storage is performed through a dozen wells (Fig. 3) alternatively used as injectors and producers. During the filling and cycling periods, pressures (Fig. 4) were recorded in 11 observation wells located throughout the site. Wells W3 and W6 are perforated in layer N2, wells W7 and W10 in layer L7 and the other observation wells in layer L8. Gas storage involves the formation of a gas bubble whose growth depends on the injection and production rates. The static pressure, that is the gas bubble pressure, was also measured during the whole production history.

TABLE 1

Petrophysical properties. Porosities belong to $[0 ; 1]$ and permeabilities express in $\mathrm{mD}$

\begin{tabular}{c|c|c|c}
\hline Layer & $\begin{array}{c}\text { Porosity } \\
\text { mean }\end{array}$ & $\begin{array}{c}\text { Porosity } \\
\text { variance }\end{array}$ & Porosity $\phi$-permeability $k$ relation \\
\hline L2 & 0.2292 & 0.00278 & $\log _{10}(k)=6.8729 \phi+0.4043$ \\
\hline L3 & 0.1763 & 0.00608 & $\log _{10}(k)=9.5409 \phi-0.3517$ \\
\hline L4 & 0.0333 & 0.00177 & $\log _{10}(k)=16.967 \phi-0.8234$ \\
\hline L5 & 0.1895 & 0.00441 & $\log _{10}(k)=11.257 \phi-0.6291$ \\
\hline L6 & 0.1637 & 0.00545 & $\log _{10}(k)=9.2728 \phi+0.1777$ \\
\hline L7 & 0.1906 & 0.00334 & $\log _{10}(k)=7.6666 \phi+0.0679$ \\
\hline L8 & 0.1834 & 0.00556 & $\log _{10}(k)=9.4154 \phi+0.5935$ \\
\hline
\end{tabular}

\section{THEORETICAL FRAMEWORK}

The following algorithms are the backbone of the AHM developed here. They allow for designing a workflow from the fine grid reservoir model to the fluid flow simulator, and for modifying the fine grid reservoir model to make it as consistent as possible with all the available data.

\subsection{FFT-MA Algorithm}

The moving average method [2] can be applied to simulate large Gaussian stationary random fields. Let us write the covariance function, $C$, as a convolution product:

$$
C=g * \breve{g}
$$

where $\breve{g}(\mathbf{x})=g(-\mathbf{x})$. Starting from a set of normal deviates (or Gaussian white noise) $z$, a Gaussian random field $y$ with mean $y_{o}$ and covariance function $C$ is built as follows:

$$
y=y_{o}+g * z
$$

This method is attractive because of the separation between the random numbers $(z)$ and the structural parameters $\left(y_{o}\right.$ and $g$, that is mean, variance, correlation lengths, etc.). However, the calculation of $g$ and the convolution product may be difficult [3]. 

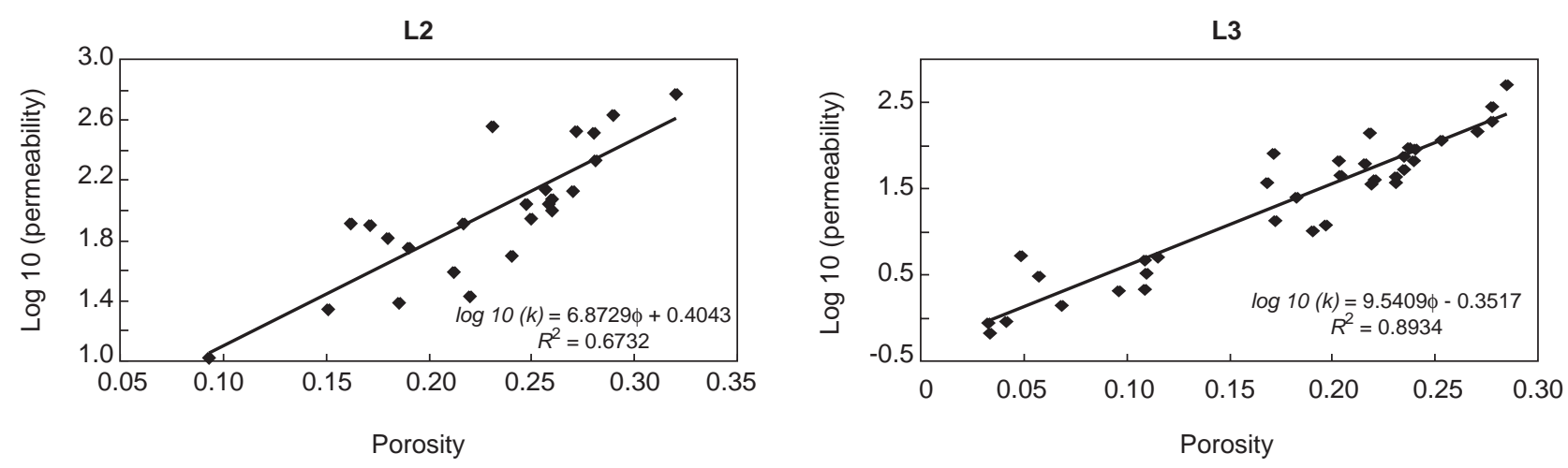

L4
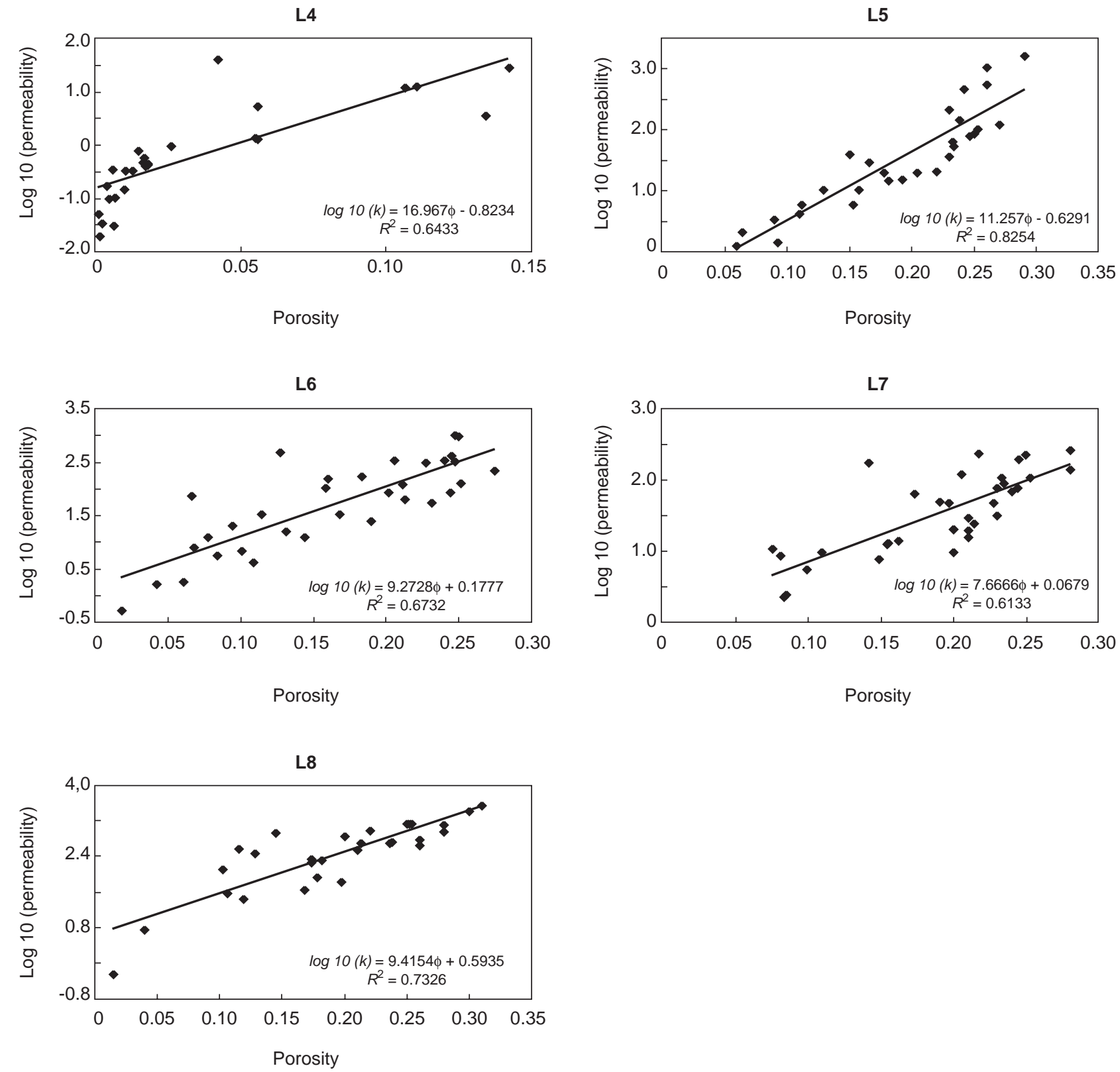

Figure 2

Porosity-permeability relationships. Porosities belong to $[0 ; 1]$ and permeabilities express in $\mathrm{mD}$. 


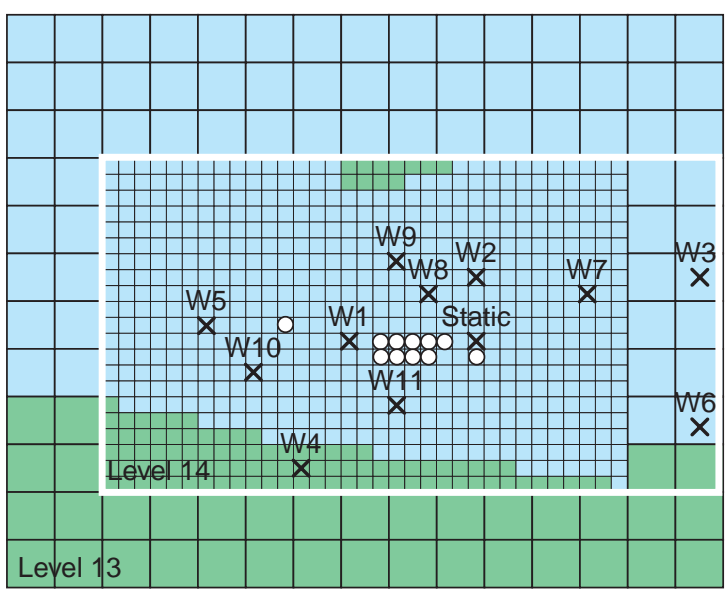

Figure 3

Location of the observation wells (groups of producers/ injectors are also indicated by circles). The white square defines the area of interest for reservoir characterization.

Therefore, we apply the Fast Fourier Transform moving average (FFT-MA) method described in [4]. The FFT-MA generator still benefits from the moving average framework, but also from discrete spectral computations. In this special case, the convolution product $g^{*} z$ is computed in the frequency domain, which is easier. The FFT-MA algorithm is fast and stable since computations are performed through FFTs. It can be used to generate large Gaussian stationary random fields. Additionally, it uncouples the random numbers from the structural parameters because of the underlying moving average background. Distinct realizations can be simulated from distinct sets of independent normal deviates, but identical structural properties: they are realizations of the same stochastic process. Similarly, the structural properties can be modified without changing the random numbers. The resulting realizations are different, but keep the same general trend.

The CPU time required to simulate a random field based on the FFT-MA algorithm is negligible. For instance, generating a field with $10^{6}$ grid blocks necessitates about $30 \mathrm{~s}$ with a standard PC.

\subsection{Gradual Deformation}

The gradual deformation method (GDM) is a geostatistical parameterization technique used to modify smoothly realizations of stochastic Gaussian or Gaussian-related models. Its basic version applies to standard normal deviates distributed as $N\left(0, \mathrm{I}_{M}\right)$. Let us consider two sets of independent standard normal deviates: a starting one, $z^{1}$, and an additional one, also termed complementary, $z^{2}$. A new set of independent standard normal deviates $z$ is obtained from:

$$
z(t)=z^{1} \cos (\pi t)+z^{2} \sin (\pi t)
$$

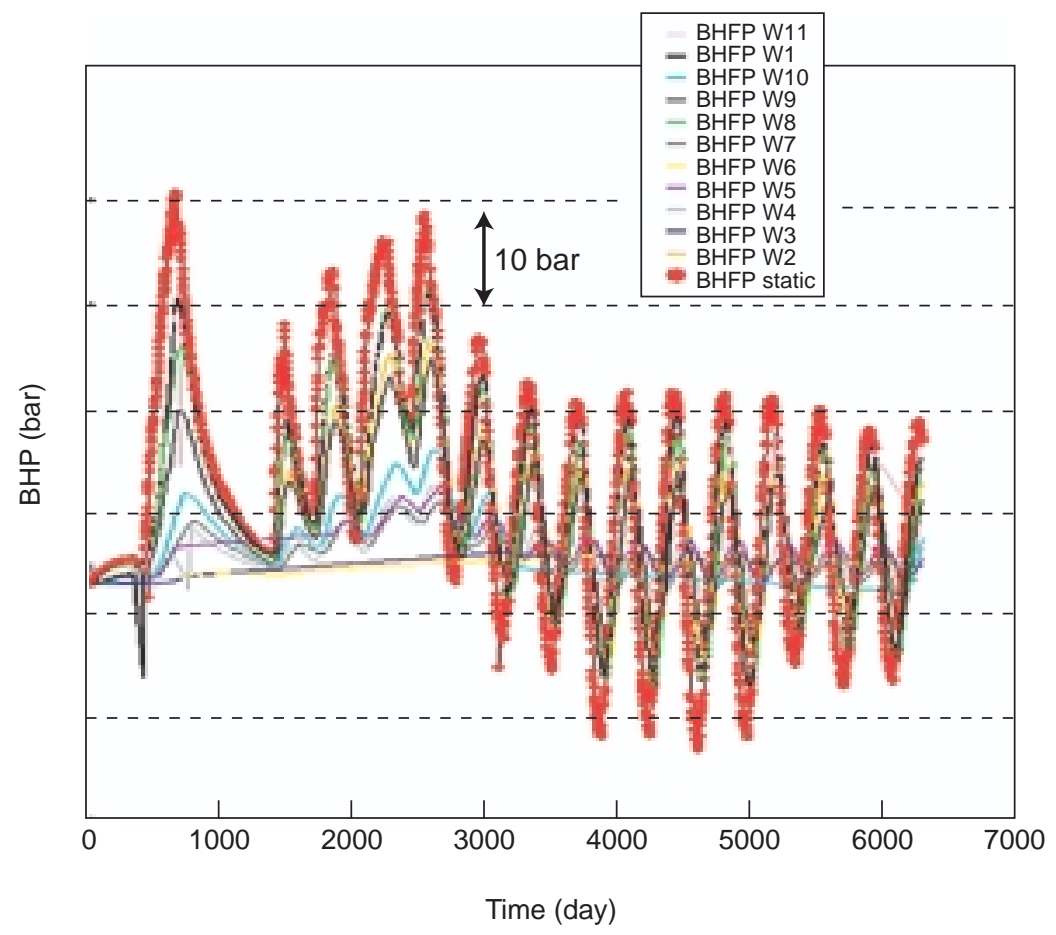

Figure 4

Static pressure and pressures measured in the 11 observation wells. 
Whatever the value of the deformation parameter $t, z$ is a set of independent standard normal deviates. As the deformation law is periodic, $t$ ranges from -1 to 1 . For $t=0, z$ is the same as the starting $z^{1}$; when $t=0.5, z$ is the same as $z^{2}$. Continuous variations in $t$ yield continuous variations in $z$. Varying $t$ provides a chain or path in the realization space.

When varying the normal deviates solely in some subdomains [5], the deformation is said to be local. In addition, this deformation technique can be easily extended to the combination of more than two sets of normal deviates [6], which implies an increase in the number of gradual deformation parameters.

\subsection{Conditioning Stochastic Realizations to Dynamic Data (Pressures)}

Geostatistical generators, such as the FFT-MA one, provide many realizations that appear equally probable when focusing on the structural information. However, these realizations do not reproduce (except by chance) the dynamic data measured at wells. Conditioning consists in adjusting the realizations so that they also comply with these measurements. Such a problem is termed an optimization problem.

An objective function is defined to measure the discrepancy between the actual reservoir and the simulated realization. The purpose of the optimization process is to adjust gradually the realization to minimize the objective function. Basically, the objective function expresses the cumulative weighted leastsquare error between simulation and measurements.

When tackled through the GDM, the optimization problem is sequentially solved. A starting set of independent normal deviates is generated. Then, a second one is drawn at random. These two sets of normal deviates are considered as the basic components for designing a path in the realization space. An optimization process is run to determine the gradual deformation parameter that minimizes the objective function when investigating this path. In other words, the gradual deformation parameter is modified in order to explore the path until an "optimal" realization is identified. As the path represents a very tiny part of the realization space, it may be of interest to iterate the search process. Thus, the starting set of normal deviates is updated to the "optimal" realization. Simultaneously, a new complementary set of normal deviates is randomly generated. The starting set and the complementary one yield a new path that can be screened again to find a realization further reducing the objective function.

When using the FFT-MA generator, the geostatistical parameters are uncoupled from the stochastic ones, that is the normal deviates. Thus, one may simultaneously optimize the stochastic realization, the mean, the variance, the correlation lengths [7] etc. At the same time, of course, one can also optimize parameters such as activity coefficients for aquifers, productivity indexes, coefficients defining petrophysical relationships between permeability and porosity etc.

\section{HISTORY MATCH}

\subsection{Definition of the Objective Function}

For the studied case, the available dynamic data are:

- the static pressure;

- the pressures measured in 11 observation wells for the first 7 years solely.

The second cycling period data set is not used at this stage: it is used in the last section for comparison purposes. In addition, a few forward fluid flow simulations pointed out the difficulty to respect the conditions about maximum flow rates at injectors/producers. Thus, an objective function $J$ was defined that accounts both for pressures and flow rates:

$$
\begin{aligned}
J & =\sum_{i} w_{i}\left(P_{S}^{\text {sim }}\left(t_{i}\right)-P_{S}^{\text {meas }}\left(t_{i}\right)\right)^{2} \\
& +\sum_{i} \sum_{j} \alpha_{i, j}\left(P_{\text {obs }}^{\text {sim }}\left(t_{i}\right)-P_{\text {obs } s_{-}}^{\text {meas }}\left(t_{i}\right)\right)^{2} \\
& +\sum_{i} \sum_{k} \beta_{i, k}\left(Q_{I P_{-} k}^{\text {sim }}\left(t_{i}\right)-Q_{I P_{-}}^{\text {meas }}\left(t_{i}\right)\right)^{2}
\end{aligned}
$$

where $P_{S}$ is the static pressure, $P_{o b s}$ is the pressure in the observation wells, and $Q_{I P}$ is the flow rate at the injectors/ producers. The superscripts "sim" and "meas" stand respectively for "simulated" and "measured", while the subscript " $S$ " refers to "static pressures". $t$ is time. Indexes $i, j$ and $k$ indicate summation over the time steps, the number of observation wells and the number of injectors/producers.

\subsection{The Modelling Workflow}

The studied UGS geomodel consists of 7 independent intervals associated to the 7 layers L2-L8. Each interval consists of $390 \times 210$ grid blocks, grid block size being $75 \mathrm{~m} \times 75 \mathrm{~m}$. There is one facies per layer.

As defined, the domain modelled extends outside level 4 which is the area where the permeability and porosity distributions have to be characterized from optimization. This alternative was preferred in order to account for the static data provided by wells in level 3 .

The entire modelling workflow is shown in Figure 5. For each layer of interest, a porosity realization is created using a "Gen" component connected to a "FFT" component. The first one creates a set of normal deviates and the second one converts this set into a correlated, nonstandard normal realization, based on the FFT-MA algorithm. The horizontal and vertical permeabilities are created in the "GeoModel" component using porosity-permeability relations and $K_{v} / K_{h}$ ratios. The petrophysical properties of interest, restricted to the 7 layers of level 4, are extracted from the "GeoModel" component using the "Slicer" component. They are then upscaled in the "PowerLaw" component before being transferred to the 


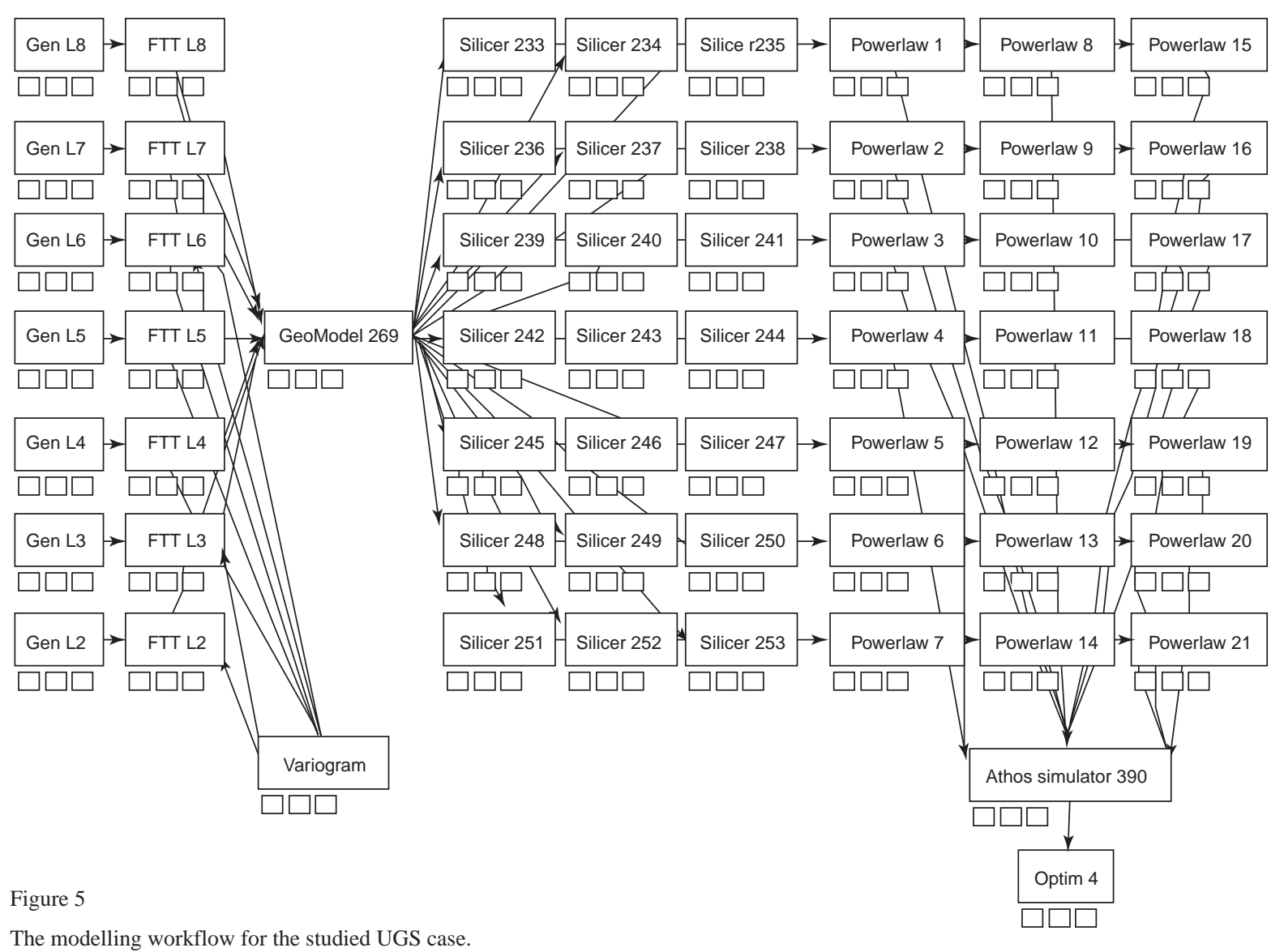

The modelling workflow for the studied UGS case.

Athos flow simulator. More precisely, the workflow built for the studied UGS case is as follows:

- We generate 7 realizations describing the porosity distributions on the basis of the FFT-MA algorithm. Each of them is connected to one of the 7 layers of the "GeoModel" component. We consider the same variogram for the 7 porosity realizations. Negative porosity values are set to 0 while porosities superior to 0.5 are set to this upper limit. In addition, the porosity realizations were constrained to the static porosity data collected at the wells.

- Once the 7 porosity realizations are built and connected to the "GeoModel", the horizontal and vertical permeabilities are also computed.

- As mentioned above, the "GeoModel" covers an area larger than level 4 . Thus, the petrophysical properties populating layers L2-L8 have to be extracted from the "GeoModel". The initial detailed realizations were generated over $390 \times 210 \times 1$ grids. We extract the values associated to $X$ cell numbers between 1 and 330 .

- The next step consists in upscaling the porosity and permeability realization. The fine grid blocks are aggregated by $10 \times 10 \times 1$. The equivalent properties of the resulting coarse grid blocks are derived from arithmetic averages for porosities and from geometric averages for horizontal and vertical permeabilities.

- When all the realizations are upscaled, they are used to feed the level 4 porosity and permeability properties required by the fluid flow simulator. Reservoir fluid flow simulations are carried out with Athos, a software developed by the IFP and Beicip-Franlab. This reservoir simulator includes the following options [8]: black-oil or compositional model, single or dual porosity medium, thermal effects, polymers, tracers.

One of the advantages of such an integrated workflow is to provide a framework to perform easily and rapidly many matching tests to refine the reservoir study. The CPU time is fully governed by the repeated flow simulations. In the studied case, a single flow simulation requires a CPU-time of about 10 min on a standard PC. Second, the strength of the workflow is to incorporate all of the steps from the fine grid reservoir modelling to the fluid flow simulator. Usually, history-matching is performed at the coarse scale only, so that the connection to the fine grid reservoir model is lost. One can determine an optimal coarse grid reservoir model, but not an optimal fine grid reservoir model. The proposed method circumvents this difficulty. At any time during the optimization process, the fine 


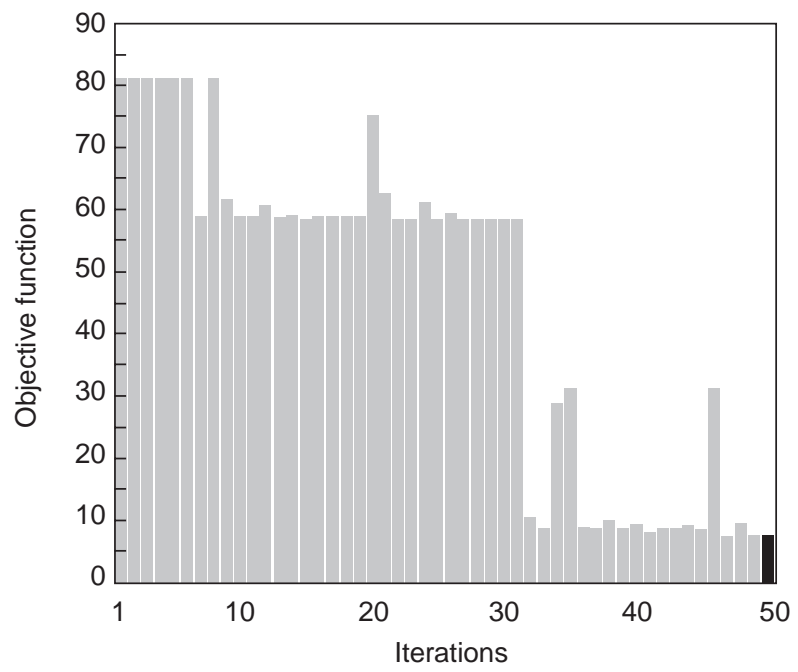

Figure 6

Objective function versus the number of fluid flow simulations for one starting experiment.

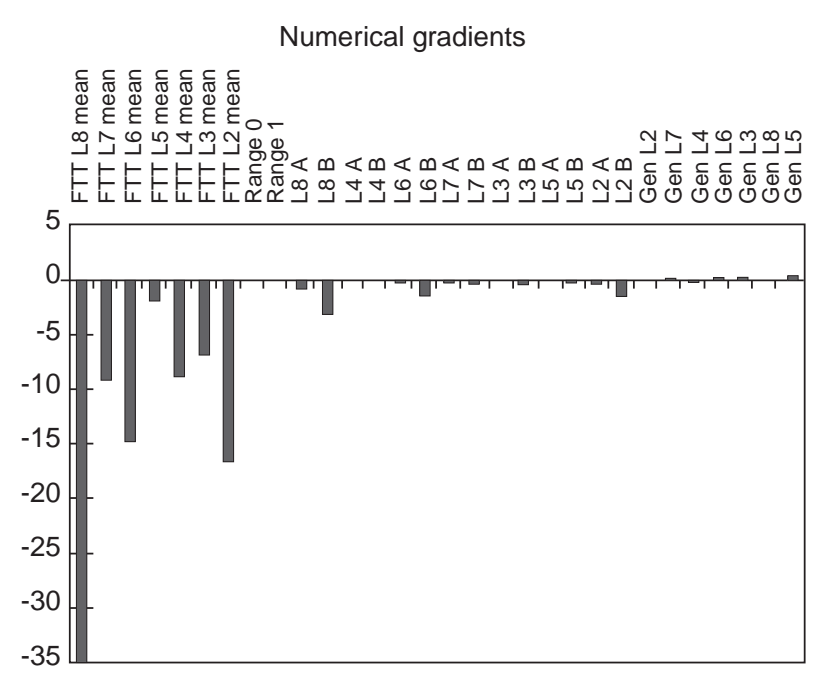

Figure 8

Numerical gradients computed at the starting guess - 1st optimization experiment.

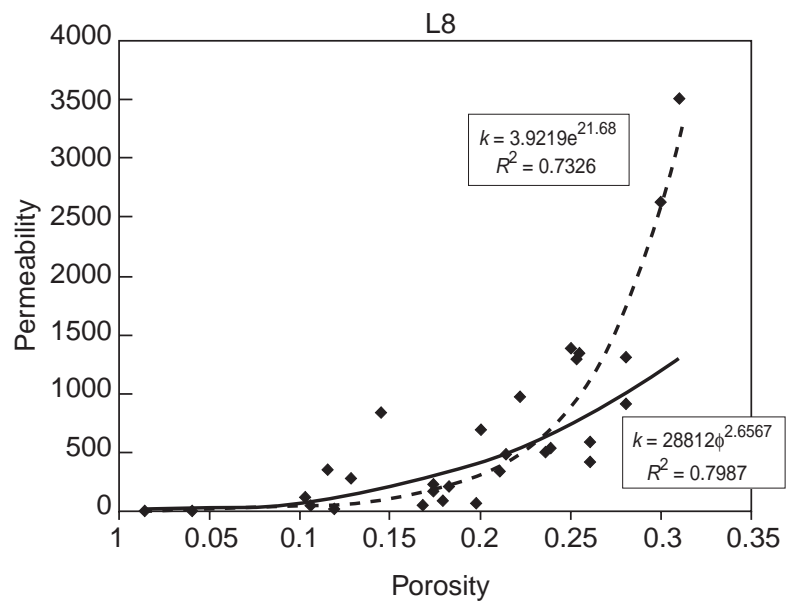

Figure 7

Relations between porosities and permeabilities (the exponential law is equivalent to the one reported in Table 1). Porosities belong to $[0 ; 1]$ and permeabilities express in $\mathrm{mD}$.

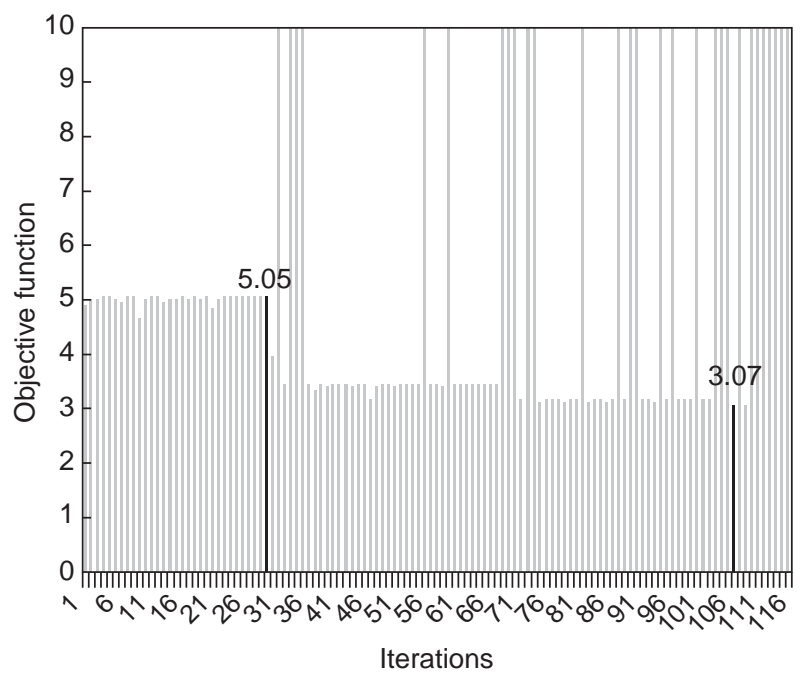

Figure 9

Objective function versus the number of fluid flow simulations - 1st optimization experiment. grid and the corresponding coarse grid reservoir models are perfectly known and consistent.

\subsection{Early Optimization Attempts}

Early matching experiments were performed optimizing only the gradual deformation parameters that govern the porosity distributions for the L2-L8 layers. The deformation was assumed to be global: each porosity realization is entirely modified from a single deformation parameter. Because the 7 layers are independent, this deformation process results in 7 deformation parameters. On the example depicted in Figure 6, three realization chains were successively investigated resulting in an objective function decrease from 81 to 7. The same experiment was repeated many times with different seeds to generate the initial sets of normal deviates. Two observations can be made. First, the decrease observed in Figure 6 was exceptional: for all our other attempts, the 
objective function never converged towards 0 . This unique behaviour was due to the fact that, for the successful case, the gradual combinations affected mainly the porosity means rather than the spatial distributions of porosity values. In other words, the first order optimization parameters are not the stochastic ones, but rather deterministic parameters that influence the porosity and permeability values. Second, the porosity-permeability relations used for these early numerical experiments were expressed as $k=\mathrm{A} \phi^{B}$ and not as reported in Table 1 . The primary reason for this choice was that it resulted in better correlation coefficients. However, a significant consequence was that the permeability values were not sufficiently high (Fig. 7) and because of this, pressure responses were very different from the real data for least at 2 wells (W7 and W10). To avoid these difficulties, the following matching studies were performed on the basis of $\log _{10}(k)=\mathrm{A} \phi+\mathrm{B}$ relations and with deterministic parameters impacting porosity and permeability values in addition to the deformation parameters.

\subsection{First Matching Study}

We selected the following parameters to be optimized:

- the mean porosity values for the L2-L8 layers, that is 7 parameters;

- the horizontal correlation lengths (ranges) describing the variogram, that is 2 parameters (the variogram model is assumed to be the same for the 7 layers);

- the $A$ and $B$ coefficients in the 7 porosity-permeability relationships, that is 14 parameters;

- the gradual deformation parameters that govern the porosity distributions for the L2-L8 layers. Again, the deformation is assumed to be global. Because the layers are considered independently, we deal with 7 deformation parameters.

Therefore, the total number of parameters was 30 .

TABLE 2

Deterministic parameter values at the beginning and at the end of the optimization processes

\begin{tabular}{|c|c|c|c|}
\hline State & Initial & $\begin{array}{l}\text { Optimal } \\
\text { first study }\end{array}$ & $\begin{array}{c}\text { Optimal } \\
\text { second study }\end{array}$ \\
\hline FFT_L8_mean: mean porosity of layer L8 & 0.1834 & 0.20419435 & 0.18962201 \\
\hline FFT_L7_mean: mean porosity of layer L7 & 0.1906 & 0.19425212 & 0.18968546 \\
\hline FFT_L6_mean: mean porosity of layer L6 & 0.1637 & 0.1796963 & 0.16281527 \\
\hline FFT_L5_mean: mean porosity of layer L5 & 0.1895 & 0.17931432 & 0.1892202 \\
\hline FFT_L4_mean: mean porosity of layer L4 & 0.0333 & 0.03036233 & 0.03308355 \\
\hline FFT_L3_mean: mean porosity of layer L3 & 0.1763 & 0.17306632 & 0.17205182 \\
\hline FFT_L2_mean: mean porosity of layer L2 & 0.2292 & 0.24100643 & 0.2282547 \\
\hline Range 0: main correlation length & 250 & 249.9992 & - \\
\hline Range 1: second correlation length & 250 & 249.9992 & - \\
\hline L8_A: $A$ coefficient for the $k-\phi$ law of layer L8 & 9.4154 & 10.761104 & 13.702663 \\
\hline L8_ $B$ : $B$ coefficient for the $k$ - $\phi$ law of layer L8 & 0.5935 & 0.6381013 & 0.55743533 \\
\hline L4_A: $A$ coefficient for the $k-\phi$ law of layer L4 & 16.967 & 16.98687 & - \\
\hline L4_B: $B$ coefficient for the $k-\phi$ law of layer L4 & -0.8234 & -0.8325772 & - \\
\hline L6_A: $A$ coefficient for the $k-\phi$ law of layer L6 & 9.2728 & 9.323828 & 8.671017 \\
\hline L6_B: $B$ coefficient for the $k-\phi$ law of layer L6 & 0.1777 & 0.17475024 & 0.16085398 \\
\hline L7_A: $A$ coefficient for the $k-\phi$ law of layer L7 & 7.6666 & 7.640175 & 8.462549 \\
\hline L7_B: $B$ coefficient for the $k-\phi$ law of layer L7 & 0.0679 & 0.056191377 & 0.07128522 \\
\hline L3_A: A coefficient for the $k-\phi$ law of layer L3 & 9.5409 & 9.512374 & 9.490515 \\
\hline L3_ $B$ : $B$ coefficient for the $k-\phi$ law of layer L3 & -0.3517 & -0.35682243 & -0.40463528 \\
\hline L5_A: $A$ coefficient for the $k-\phi$ law of layer L5 & 11.257 & 11.269428 & 11.080508 \\
\hline L5_ $B$ : $B$ coefficient for the $k-\phi$ law of layer L5 & -0.6291 & -0.64304227 & -0.685935 \\
\hline L2_A: $A$ coefficient for the $k-\phi$ law of layer $\mathrm{L} 2$ & 6.8729 & 6.9258037 & 7.1191397 \\
\hline L2 $\_B: B$ coefficient for the $k-\phi$ law of layer L2 & 0.4043 & 0.4020811 & 0.4100515 \\
\hline
\end{tabular}




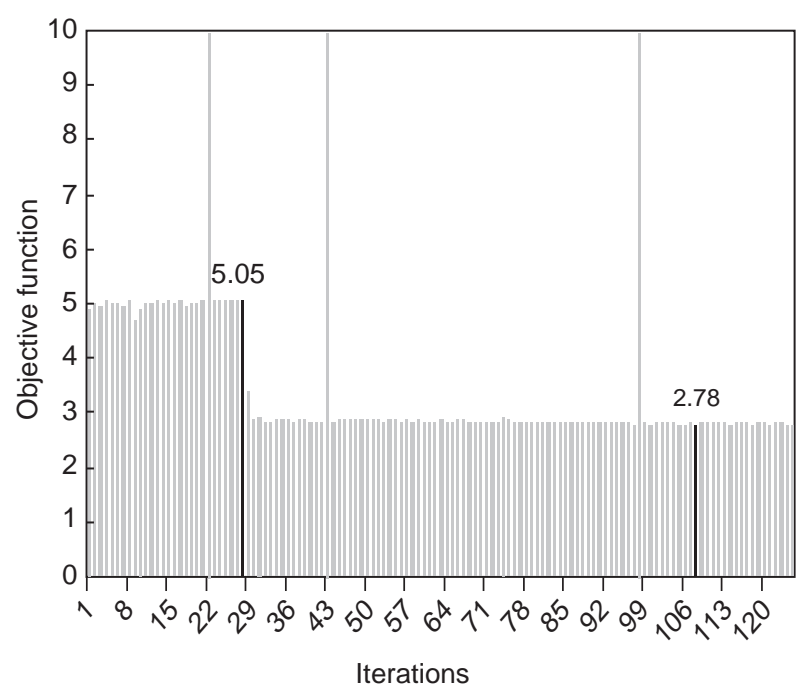

Figure 10

Objective function versus the number of fluid flow simulations - $2^{\text {nd }}$ optimization.

The selected minimization process was based upon the Powell algorithm, which requires the gradients of the objective function relatively to the 30 parameters. As the fluid flow simulator does not allow for computing these gradients, they were approximated by numerical gradients. Following the gradual deformation procedure, we successively investigated chains of realizations, attempting to reduce further and further the objective function. Investigating a single chain involves a minimization process. Investigating 3 chains requires the launch of 3 successive minimization processes.
Prior to each of these, 30 forward fluid flow simulations are run in order to determine the gradients.

Considering the previously mentioned parameters, we run 3 optimization processes to investigate 3 successive chains of realizations and identify the reservoir model that induces the strongest decrease in the objective function. Figure 8 shows the numerical gradients computed for the starting guess: they provide information about the local sensitivity of the objective function relative to the 30 selected parameters. The gradients show that:

- the porosity means are very influential parameters;

- the two horizontal correlation lengths characterizing the variogram model as well as coefficients $A$ and $B$ specifying the porosity-permeability relation for layer $\mathrm{L} 4$ are negligible. Such observations were expected. First, the starting correlation lengths $(250 \mathrm{~m})$ are smaller that the size of the coarse grid blocks $(750 \mathrm{~m})$. Second, layer L4 represents a barrier to flow.

The behaviour of the objective function throughout the minimization process is depicted in Figure 9. The 3 succes sive decreasing steps show the gradual deformation approach. The objective function decreases by about $40 \%$ in 108 forward fluid flow simulations. We observed, mainly at the end of the history-matching process, that many simulations resulted in an unexpectedly high objective function. Two of these cases were due to numerical convergence problems that prevented the fluid flow simulator from terminating. The other high values are due to the producing well with the highest $X$ coordinates. In some conditions, this well does not succeed in flowing at the desired maximal flow rate. The mismatch emerges for a single time, but is sufficient to produce a significant increase in the objective function: we simulate a 0 flow rate instead of the expected $140 \mathrm{~m}^{3} /$ day.
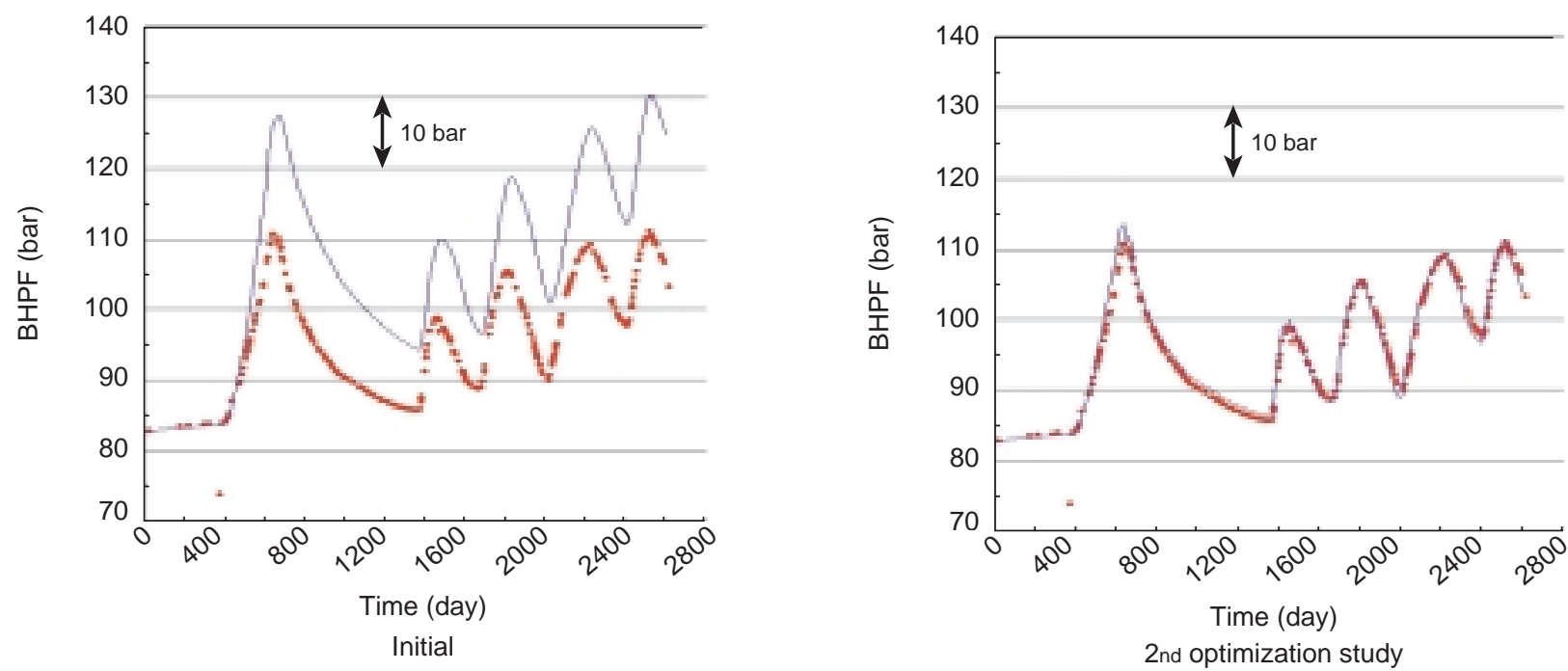

Figure 11

Measured (dots) and simulated (line) pressure at well W1 before and after performing history-match ( $2^{\text {nd }}$ study). 

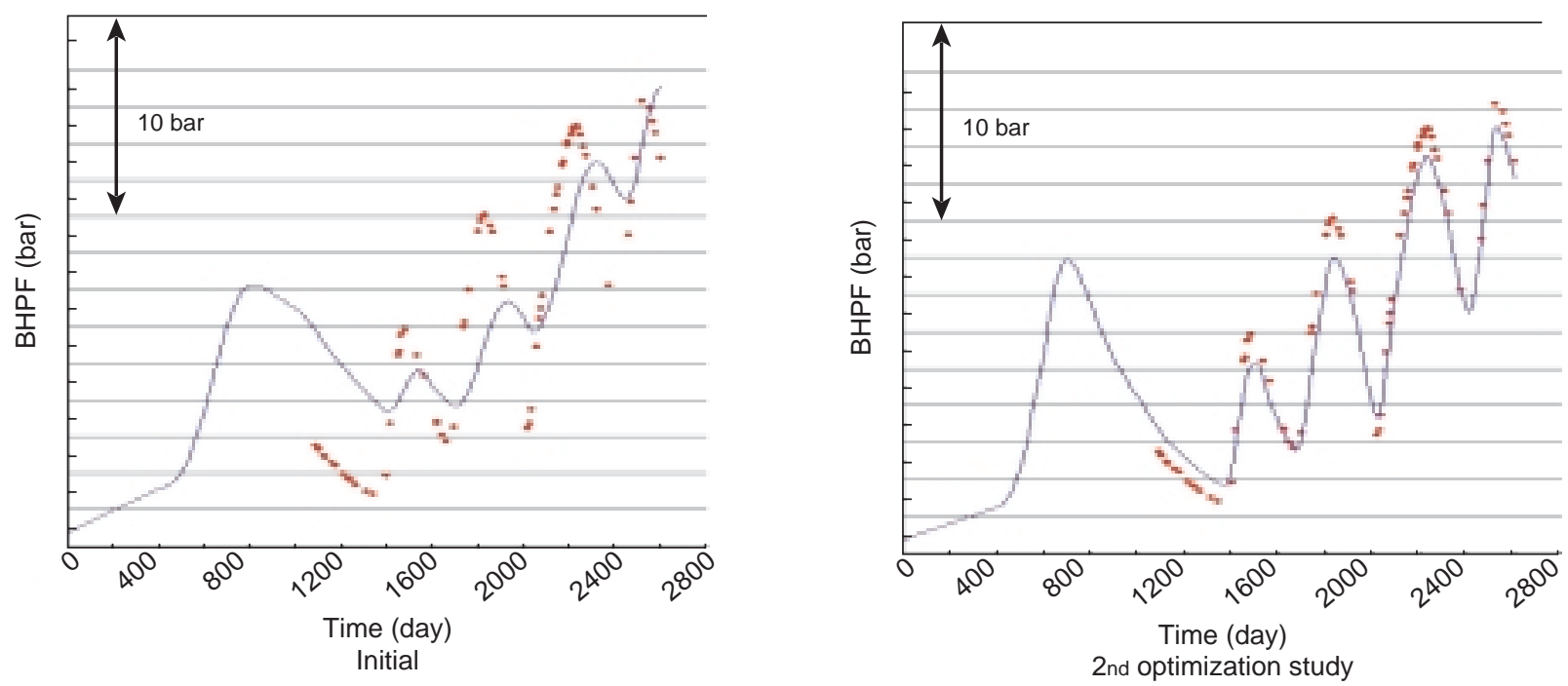

Figure 12

Measured (dots) and simulated (line) pressure at well W2 before and after performing history-match ( $2^{\text {nd }}$ study).
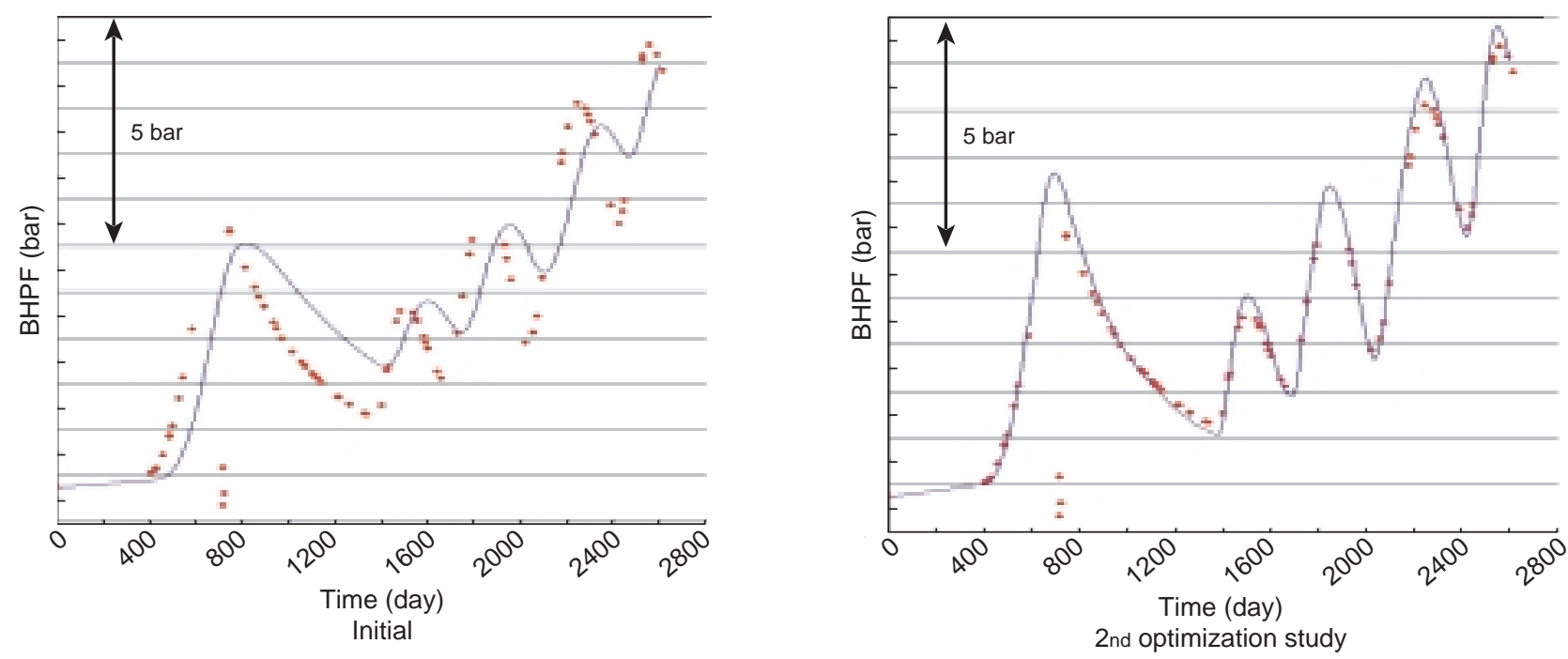

Figure 13

Measured (dots) and simulated (line) pressure at well W4 before and after performing history-match ( $2^{\text {nd }}$ study).

Note that this producing flow rate is much smaller than the others involved during the production history.

The relative variations in the objective function and the deterministic parameters computed after the exploration of 1 and 3 realization chains are reported in Table 2 . Investigating one chain induces a $30 \%$ decrease of the objective function and 3 successive chains a $40 \%$ decrease. The optimization process of the first chain ensures most of the decrease. The deterministic parameters (mainly the most influential) change during the first chain, and then remain constant for the two successive ones. The only parameters that still contribute to the matching during the two other chain investigations are the $A$ and $B$ coefficients for layer L8 and the gradual deformation parameters. This allows for assessing qualitatively the impact of the gradual deformation.

\subsection{Second Matching Study}

Because one of the producing wells had difficulties to reach the flow rate conditions (see $1^{\text {st }}$ study), its productivity index was modified by a factor of 5. This change allows us to avoid the problem. Then, the matching process was repeated based 

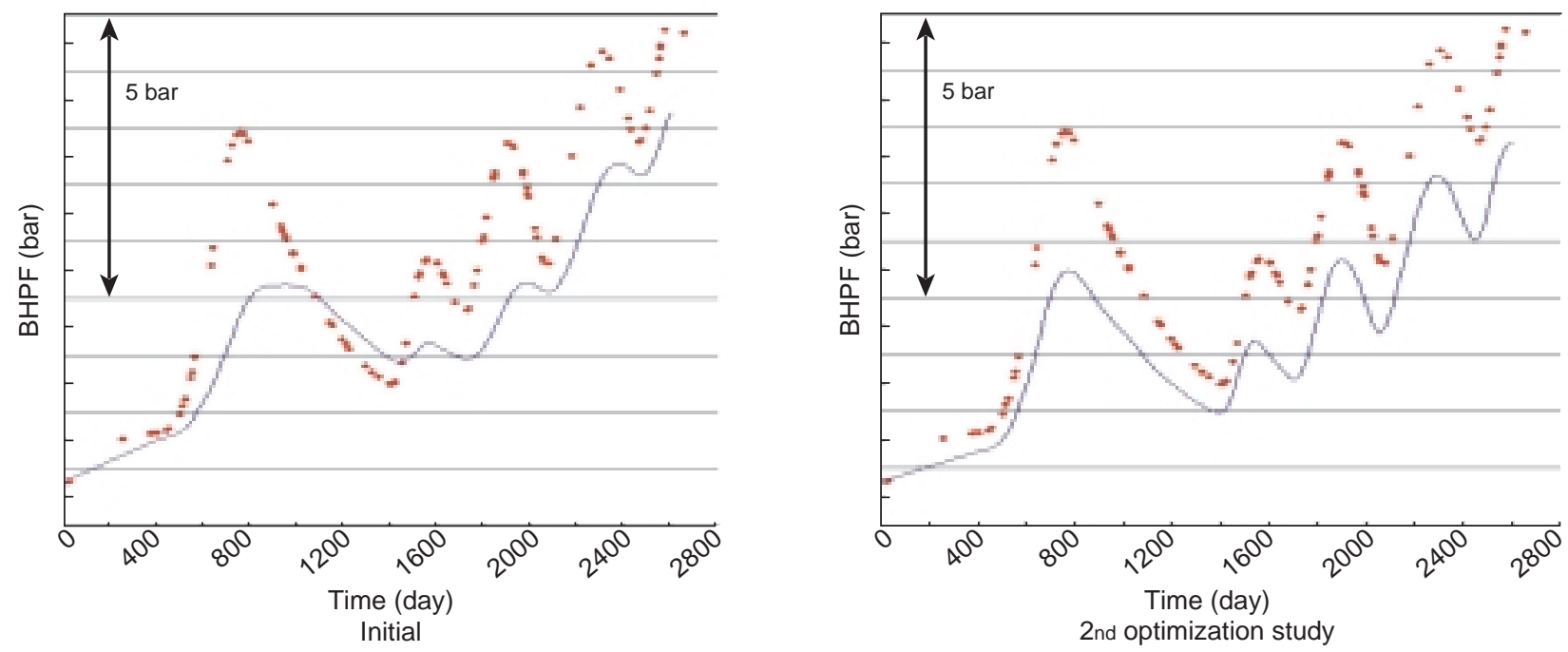

Figure 14

Measured (dots) and simulated (line) pressure at well W7 before and after performing history-match (2 ${ }^{\text {nd }}$ study).
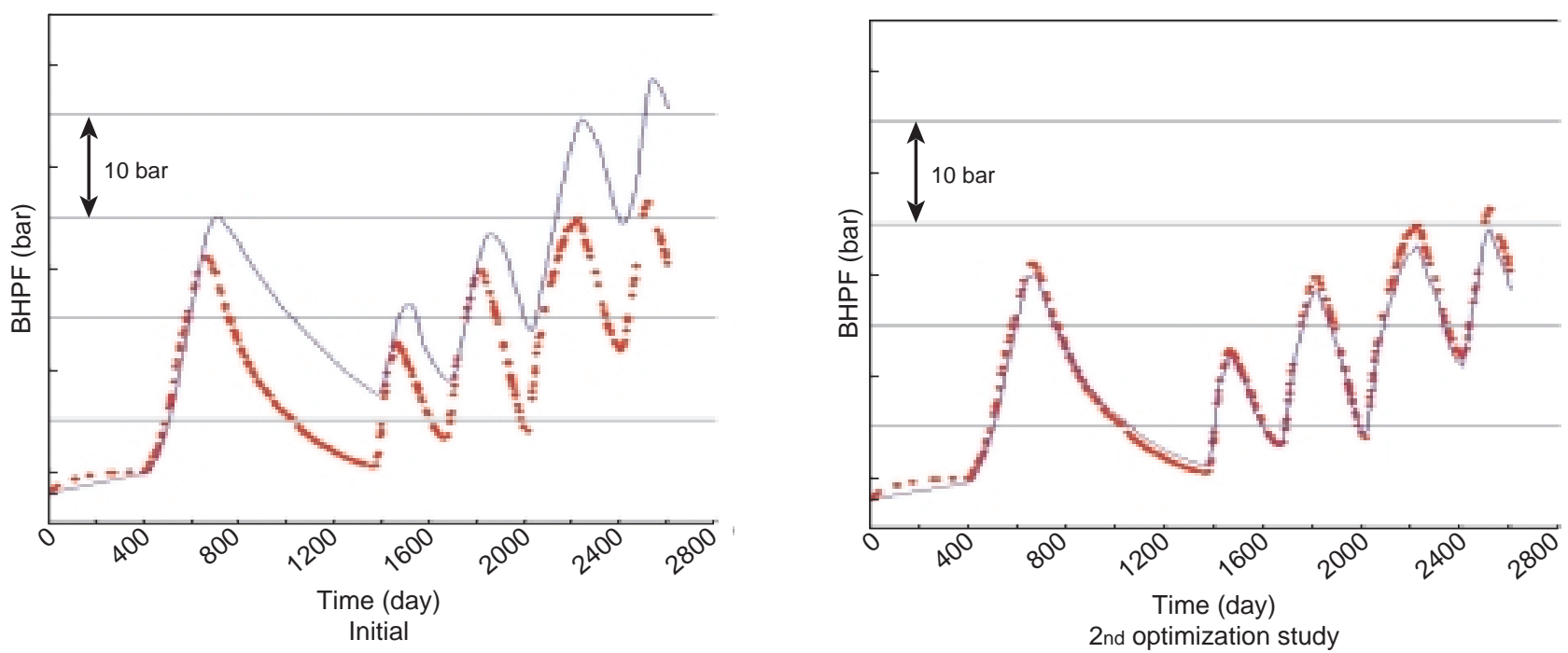

Figure 15

Measured (dots) and simulated (line) pressure at well W8 before and after performing history-match ( $2^{\text {nd }}$ study).

upon the same parameters minus the 4 negligible ones (correlation lengths and coefficients $A$ and $B$ for layer L4). Four realization chains were investigated. The behaviour of the objective function against the number of fluid flow simulations is depicted in Figure 10. There are still 3 unexpected very high values: they depend on numerical convergence problems that stop the fluid flow simulator. Most of the objective function decrease is ensured by the investigation of the $1^{\text {st }}$ chain. This $2^{\text {nd }}$ optimization experiment results in a matching improvement of $45 \%$ (the $1^{\text {st }}$ one produces an improvement of 40\%). Compared to the first matching study, the second yields a significant improvement even if the variation in the objective function is minor. Pressure calibration is good for all of the wells, except well W7. A few examples are shown from Figure 11 to Figure 16. Briefly, the AHM process was able to reproduce correctly the phases and the amplitudes of the observed pressure responses. The poor fit obtained at well W7 could be due to a geological feature that was not accounted for in our geological description. The optimal deterministic parameters are detailed in Table 2. 

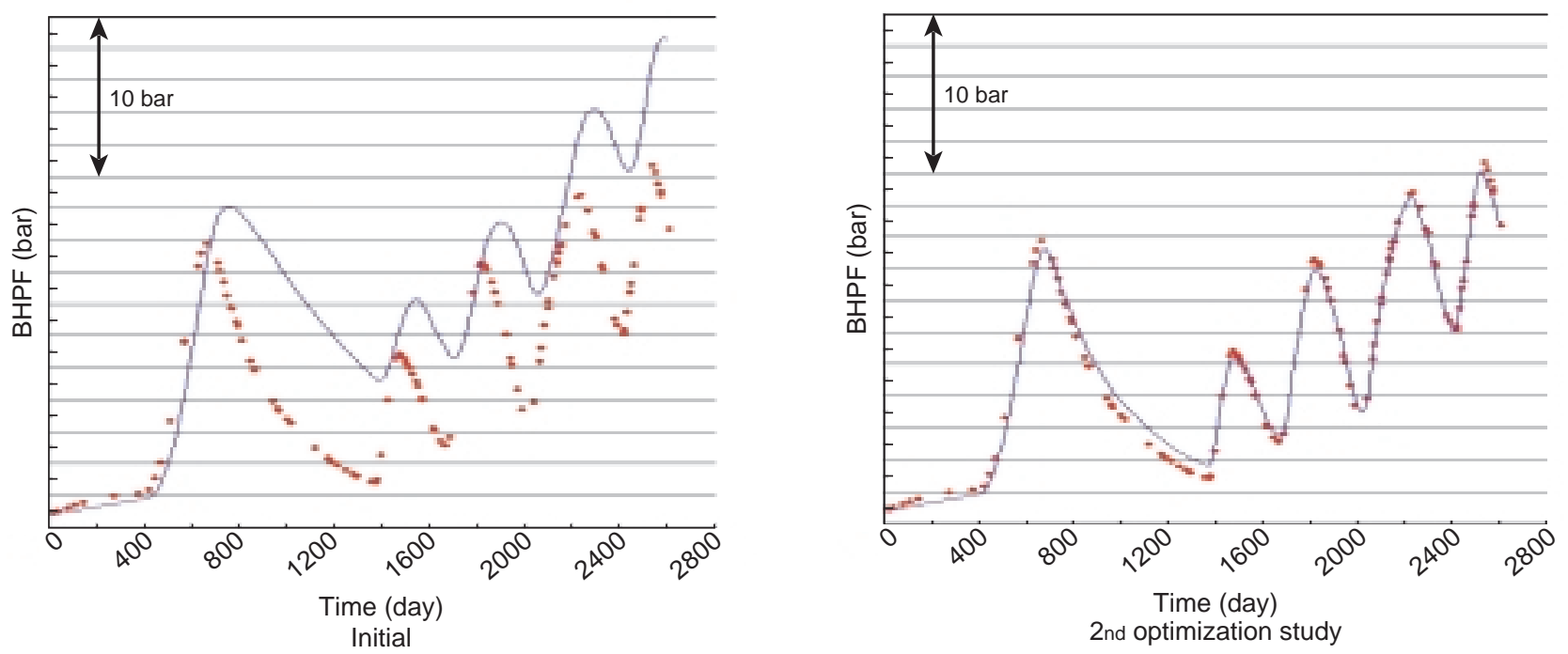

Figure 16

Measured (dots) and simulated (line) pressure at well W9 before and after performing history-match ( $2^{\text {nd }}$ study).

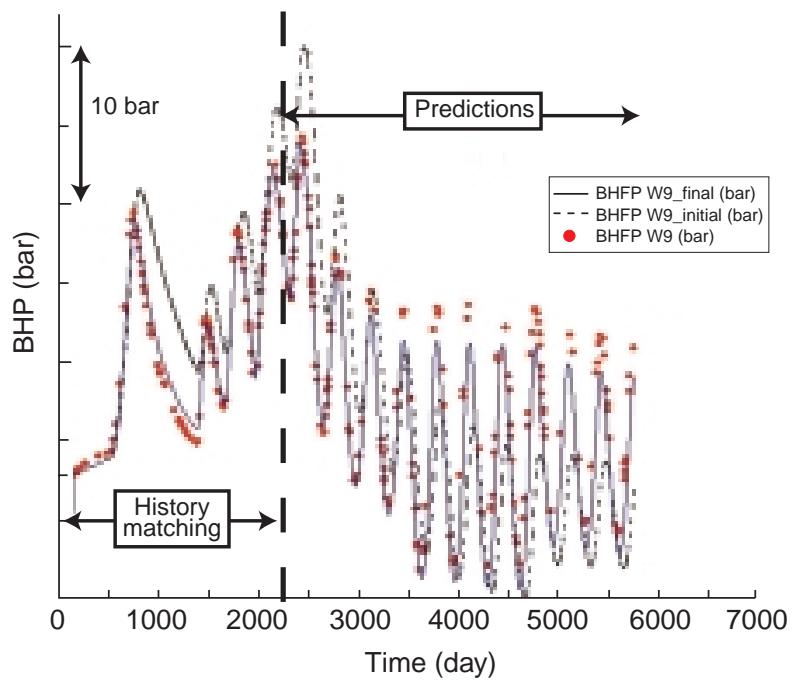

Figure 17

Comparison of the measured and simulated pressures for well W9. (Dots: data; solid line: simulation for the optimal reservoir model; dashed line: simulation for the initial reservoir model).

\section{IMPACT ON UNCERTAINTY}

The matching process was performed based upon the pressures measured during the first 7 years solely, that is the filling period. We did not include the data collected during the following cycling period in the objective function. Now, in order to appreciate the benefit of history-matching, we simulate these cycling data with the starting reservoir model and the optimal one identified during the $2^{\text {nd }}$ matching study. The starting model is constrained to the static data and the optimal to the static data plus the pressures obtained during the first 7 years. This is thus an attempt at prediction. How these two models are capable of estimating the pressures over the last 10 years? For almost all of the wells, the difference between the measured and simulated cycling pressures of the second period was much smaller for the optimal reservoir model than for the initial one. An example is given in Figure 17, which points out the interest of history-matching.

\section{CONCLUSIONS}

An assisted history matching (AHM) involving simultaneously stochastic and deterministic parameters was successfully applied to integrate structural data and pressures in the modelling of an underground gas storage. A small number of deterministic parameters, related to porosity and permeability, were shown to have a significant impact on the matching process: they acted as first order parameters. On the other hand, the use of gradual deformation parameters added a stochastic dimension and allowed for refining further the match when possible. However, in this case, they remain second order parameters, because the correlation lengths were smaller than the size of the coarse grid blocks. All of the pressure responses were correctly reproduced in terms of phases and amplitudes except at well W7. 
The AHM methodology developed appears to be especially powerful for:

- managing a workflow integrating every steps from fine grid model creation to fluid flow simulation;

- handling rapid history matching tests;

- analyzing the influence of several deterministic and stochastic parameters;

- determining fine grid reservoir models consistent with all the available static and dynamic data; and lastly for

- reducing uncertainty in predictions.

\section{ACKNOWLEDGEMENTS}

The authors thank the IFP and Gaz de France for permission to publish this paper.

This work has been performed within the framework of the Condor joint industry project. The authors thank the participating companies for their support: Groupement Berkine, BHP-Billiton, BP, Eni-Agip, Gaz de France, Pemex, Petrobras, ConocoPhillips and Total.

\section{REFERENCES}

$1 \mathrm{Hu}$, L.Y. (2000) Gradual deformation and iterative calibration of Gaussian-related stochastic models. Math. Geol., 32, 1, 87-108.

2 Journel, A., and Huijbregts, C.J. (1978) Mining Geostatistics. Academic Press, London.

3 Oliver, D.S. (1995) Moving averages for Gaussian simulation in two and three dimensions. Math. Geol., 27, 8, 939-960.

4 Le Ravalec, M., Notinger, B., and Hu, L.-Y. (2000) The FFT-Moving Average (FFT-MA) generator: an efficient tool for generating and conditioning Gaussian simulations. Math. Geol., 32, 6, 701-723.

5 Le Ravalec-Dupin, M., Nœtinger, B., Hu, L.Y., and Blanc, G. (2001) Conditioning to dynamic data: an improved zonation approach. Petroleum Geosciences, 7, S9-S16.

6 Roggero, F., and Hu, L. (1998) Gradual deformation of continuous geostatistical models for history matching. SPE 49004, SPE Ann. Tech. Conf. and Exhib., New Orleans, LA.

7 Le Ravalec, M., Hu, L.Y., and Nœtinger, B. (2001) Stochastic Reservoir Modeling Constrained to Dynamic Data: Local Calibration and Inference of the Structural Parameters. SPE Journal, 25-31, March.

8 Beicip-Franlab (2004) Athos User's Guide, Version 4.3.

Final manuscript received in October 2004 